International Journal of Medical Anesthesiology 2021; 4(1): 11-13

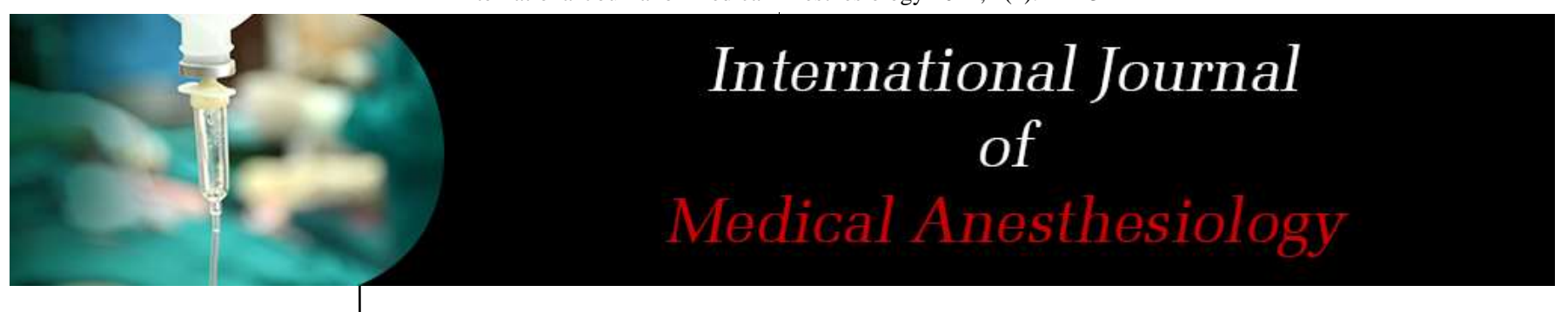

E-ISSN: 2664-3774

P-ISSN: 2664-3766 www.anesthesiologypaper.com IJMA 2021; 4(1): 11-13

Received: 28-10-2020

Accepted: 08-12-2020

Dr. Shwethapriya $\mathbf{R}$ Associate Professor, Department of Critical Care, KMC Manipal, MAHE University, Karnataka, India

Dr. Manjunath Prabhu Professor, Department of Anesthesiology, KMC Manipal, MAHE University, Karnataka, India

Dr. Souvik Chaudhury Assistant Professor, Department of Critical Care, KMC Manipal, MAHE University, Karnataka, India

Corresponding Author: Dr. Shwethapriya $\mathbf{R}$ Associate Professor, Department of Critical Care, KMC Manipal, MAHE University, Karnataka, India

\section{Blind and lightwand guided tracheal intubation: Incidence of esophageal intubation}

\author{
Dr. Shwethapriya R, Dr. Manjunath Prabhu and Dr. Souvik Chaudhury
}

DOI: https://doi.org/10.33545/26643766.2021.v4.i1a.188

\begin{abstract}
The ILMA is a modification of the laryngeal mask airway and performs as an effective supraglottic airway device. It is also designed to serve as a conduit for orotracheal intubation. Intubation through the ILMA is usually a blind procedure. However, blind intubation may at times be unsuccessful. Devices such as the fibreoptic bronchoscope and the lightwand have been shown to improve success rates of intubation through the ILMA. This randomized study was conducted on 60 adult patients with normal airways undergoing scheduled surgery under general anaesthesia. Patients in the blind group (n $=30)$ were intubated blindly through the ILMA and patients in the lightwand group $(\mathrm{n}=30)$ were intubated via the ILMA using lightwand without the inner stylet. Five patients had modified Mallampati equivalent to class III, and they were evenly distributed between the two groups. Other airway parameters in these five patients were within normal limits and they were not anticipated to have difficult airways. No patient belonging to modified Mallampati class $1 \mathrm{~V}$ was involved in the study.
\end{abstract}

Keywords: Blind and lightwand, tracheal intubation, esophageal intubation

\section{Introduction}

The difficult airway is a phenomenon often encountered by anaesthesiologists. At times, the difficult airway may be evident during the preanaesthetic assessment and this helps in planning airway management prior to a procedure. Less frequently, it crops up in an unpredictable manner, either while administering anaesthesia or in an emergency setting. Whether anticipated or not, direct laryngoscopy and visualization of the glottis often fails in the event of a difficult airway ${ }^{[1]}$.

Several alternative airway devices and techniques are employed in such situations. The intubating laryngeal mask airway (ILMA) and the illuminated stylet are two such airway devices that have gained popularity in a difficult airway scenario.

The ILMA is a modification of the laryngeal mask airway and performs as an effective supraglottic airway device. It is also designed to serve as a conduit for orotracheal intubation. Intubation through the ILMA is usually a blind procedure. However, blind intubation may at times be unsuccessful ${ }^{[1]}$. Devices such as the fibreoptic bronchoscope and the lightwand have been shown to improve success rates of intubation through the ILMA ${ }^{[2,3]}$.

The lightwand is an illuminated stylet, which can be a useful instrument for both oral and nasal intubations ${ }^{[4]}$. It relies on transillumination of the anterior neck tissues to facilitate the correct placement of an endotracheal tube. When used alone, the success rate of intubation with lightwand is $90 \%{ }^{[5,6]}$. We postulated that being complementary to each other, the combined use of ILMA and lightwand might improve the success rate of intubation.

\section{Methodology}

This randomized study was conducted on 60 adult patients with normal airways undergoing scheduled surgery under general anaesthesia. Patients in the blind group $(n=30)$ were intubated blindly through the ILMA and patients in the lightwand group $(n=30)$ were intubated via the ILMA using lightwand without the inner stylet. Patients in both the groups were compared with respect to demographic parameters, success rate of ILMA insertion, time taken for ILMA insertion, success rate of intubation through the ILMA and time for intubation, number of attempts for successful intubation, adjustment manoeuvres required, incidence of esophageal intubations and laryngopharyngeal morbidity. 
Patients were randomly allocated to one of two equal sized groups ( $n=30$ each). A random number table was used for randomization and they were divided to one of the following two groups.

1. Blind: patients were blindly intubated through the ILMA (LMA Fastrach ${ }^{\mathrm{TM}}$, Laryngeal MASK Company Limited, Henley-on-Thames, UK).

2. Lightwand: Trachlight ${ }^{\mathrm{TM}}$ (Laryngeal Medical Corporation, New York, USA), without the inner metal stylet, was used as a guide for intubation through the ILMA.

\section{Results}

A total of 60 patients were enrolled in the study, and were randomly allocated to either Blind group where blind intubation was done through the intubating laryngeal mask airway (ILMA) or Lightwand group where lightwand guided intubations were performed through the ILMA. Each group consisted of 30 patients $(n=30)$.

Both the groups were comparable with respect to age, weight, height and body mass index. The male to female ratio was similar in both groups. There was also a comparable proportion of ASA physical status 1 and II patients in both the groups.

Table 1: Demographic data and ASA physical status

\begin{tabular}{|c|c|c|c|}
\hline Parameter & Blind $(\mathbf{n}=\mathbf{3 0})$ & Lightwand (30) & p value \\
\hline Age (years) Mean \pm S.D & $34 \pm 9$ & $35 \pm 12$ & $0.71^{*}(\mathrm{NS})$ \\
\hline Weight Mean \pm S.D & $55.2 \pm 9.05$ & $55.2 \pm 8.83$ & $1.00^{*}(\mathrm{NS})$ \\
\hline Height Mean \pm S.D & $155 \pm 5.5$ & $154 \pm 5.0$ & $0.46^{*}(\mathrm{NS})$ \\
\hline Body mass index $\left(\mathrm{kg} / \mathrm{m}^{2}\right)$ Mean \pm S.D & $22.36 \pm 3.14$ & $23.08 \pm 2.91$ & $0.13^{*}(\mathrm{NS})$ \\
\hline Gender: male & 8 & 7 & \\
\hline Female & 22 & 23 & \\
\hline ASAPS I & 25 & 27 & \\
\hline ASAPS II & 5 & 3 & \\
\hline
\end{tabular}

S.D: standard deviation, NS: not statistically significant

* Student's unpaired $t$ test

Table 2: Modified Mallampati Classification of patients

\begin{tabular}{|c|c|c|}
\hline $\begin{array}{c}\text { Modified Mallampati } \\
\text { Class }\end{array}$ & $\begin{array}{c}\text { Blind group } \\
(\mathbf{n}=\mathbf{3 0})\end{array}$ & $\begin{array}{c}\text { Lightwand group } \\
(\mathbf{n}=\mathbf{3 0})\end{array}$ \\
\hline 1 & 9 & 9 \\
\hline II & 19 & 18 \\
\hline III & 2 & 3 \\
\hline
\end{tabular}

As shown in table 2, five patients had modified Mallampati equivalent to class III, and they were evenly distributed between the two groups. Other airway parameters in these five patients were within normal limits and they were not anticipated to have difficult airways. No patient belonging to modified Mallampati class $1 \mathrm{~V}$ was involved in the study.

Table 3: Incidence of oesophageal intubation

\begin{tabular}{|c|c|c|c|}
\hline Parameters & $\begin{array}{c}\text { Blind group } \\
\mathbf{n = 3 0}\end{array}$ & $\begin{array}{c}\text { Lightwand } \\
\text { group } \mathbf{n = 3 0}\end{array}$ & $\begin{array}{c}\mathbf{p} \\
\text { value }\end{array}$ \\
\hline $\begin{array}{c}\text { Number of oesophageal } \\
\text { intubations }\end{array}$ & 7 & 0 & $0.01^{\#}$ \\
\hline
\end{tabular}

\# Fisher's exact test

In the blind group, there were 7 episodes of oesophageal intubation in 6 patients. In one patient, oesophageal intubation occurred twice. This difference in the incidence of oesophageal intubations was statistically significant with a $\mathrm{p}$ value of 0.01 .

\section{Discussion}

The first prototype of the intubating laryngeal mask airway (ILMA) was conceived in 1989. As studies on the ILMA progressed and its design features were refined, it was found to have greater potential than the earlier LMA classic ${ }^{\mathrm{TM}}$ in management of the difficult airway. The ILMA (LMA Fastrach, Laryngeal Mask Company Limited, Henley-onThames, UK) was found to form a more effective seal with the glottis ${ }^{[7]}$, insertion of the ILMA was easier and quicker ${ }^{[8]}$ and insertion with the head in the neutral position was possible ${ }^{[9]}$.

The ILMA is not only a supraglottic ventilation device, but it also acts as a conduit for tracheal intubation and its use is highly recommended in patients with difficult airway ${ }^{[10]}$. Although earlier studies have shown that blind advancement of a tracheal tube (TT) through the ILMA was successful in intubating the trachea in $90-96 \%$ of patients, first attempt success rates can be higher when additional aids like lightwands, optical stylets or fibreoptic bronchoscope are used. Various guidelines recommend not to use blind intubation through ILMA, especially in patients with anticipated difficult airway.

In our study, we observed 7 episodes of oesophageal intubation. All these 7 incidences occurring in 6 patients (one patient had two episodes), belonged to the blind group. There was no oesophageal intubation in the lightwand group. This observation agrees with earlier reports ${ }^{[2,6]}$.

The above result is one of the most important advantages of the lightwand guided technique over the blind technique. Accidental oesophageal intubation has several disadvantages. It not only delays the process of intubation but it can also increase the chances of regurgitation or oesophageal injury. The lightwand helps to avoid such harmful events.

With regards to adverse events there was no significant difference between the two methods of intubation. None of the patients had an episode of desaturation. The number of patients who had blood on the ILMA and/or on the TT on removal was comparable in both the groups. Likewise, there was no difference in the incidence of postoperative sore throat or hoarseness of voice between the blind and lightwand groups.

\section{Conclusion}

In the blind group, there were 7 episodes of oesophageal intubation in 6 patients. In one patient, oesophageal intubation occurred twice. 


\section{References}

1. Caponas G, Popat M. Difficulty in use and device failure with the intubating laryngeal mask airway. Eur J Anaesthesiol 2002;19:764-6.

2. Chan PL, Lee TW, Lam KK, Chan WS. Intubation Through Intubating Laryngeal Mask with and without a Lightwand: A Randomized Comparison. Anaesth Intensive Care 2001;29:255-259.

3. Joo, Hwan S, Rose, Keith D. The Intubating Laryngeal Mask Airway With and Without Fiberoptic Guidance. Anesthesia \& Analgesia: March 1999;88(3):662-666.

4. Orlando RH, Saul Pytka, Ian Morris, et al. Lightwand intubation: II - Clinical trial of a new lightwand for tracheal intubation in patients with difficult airways. Canadian Journal of Anaesthesia 1995;42:826.

5. Lipp M, de Rossi L, Daublander M, Thierbach A. The transillumination technique. An alternative to conventional intubation? Anaesthetist 1996;45:923-30.

6. Kihara S, Watanabe S, Taguchi N. A comparison of blind and lightwand-guided tracheal intubation through the intubating laryngeal mask. Anaesthesia 2000;55:427-31.

7. Keller C, Brimacombe J. Pharyngeal Mucosal Pressures, Airway Sealing Pressures, and Fiberoptic Position with the Intubating versus the Standard Laryngeal Mask Airway. Anesthesiology 1999;90:1001-1006.

8. Choyce A, Avidan MS, Patel C. A Harvey Comparison of laryngeal mask and intubating laryngeal mask insertion by the naïve intubator. $\mathrm{Br} J$ Anaesth 2000;84:103-5.

9. Asai T, Wagle AU, Stacey M. Placement of the intubating laryngeal mask is easier than the laryngeal mask during manual in-line neck stabilization. $\mathrm{Br} \mathrm{J}$ Anaesth 1999;82(5):712-4.

10. Ferson DZ, Rosenblatt WH, Johansen MJ, Osborn I, Ovassapian A. Use of the Intubating LMA-Fastrach ${ }^{\text {TM }}$ in 254 Patients with Difficult-to-manage Airways. Anesthesiology 2001;95(5):1175-81. https:// doi.org/10.1097/00000542-200111000-00022 PMid:11684987. 